\title{
The Literature Review about Education Function
}

\author{
Yin Guoqing \\ Yunnan University of Finance and Economics \\ Kunming, China \\ 459046811@qq.com
}

\author{
Bao Jili* \\ Yunnan University of Finance and Economics \\ Kunming, China \\ 1466931184@qq.com
}

\begin{abstract}
From Tao Xingzhi proposed that education is the foundation of their nation to now implement the strategy of rejuvenating the country through science and education; it is obvious that education is important. During the transformation period, education is the basic category to push forward various reforms. Based on the present situation of country and society, it is the premise and fundamental that thorough grasps and understands the definition of education's function to promote the advancement of our nation. This paper combed through the domestic and foreign research achievements about the function of education, briefly summarizes each kinds of ideas about the positive function and negative function of education.
\end{abstract}

Keywords-the function of education; positive function; negative function

\section{INTRODUCTION}

From the Renaissance to the glorious revolution, then to the industrial revolution, is such a development path that thoughtsystem- implement. It contributed to the strong of Britain and even the entire Western Europe, the qualitative change of the world pattern and the human history. In contrast, in the process of the history of China, from the westernization Movement to the Xinhai Revolution, then to the new culture Movement, the trajectory is opposite to the situation of the Western Europe. The impartial arbiter - the history sentence for such a path is impracticable, because prosperity of any country and nation is inseparable from individuals' thought awareness and groups' exploration of the unknown. The United States from the earlier a deviation from the center, enslaved land of barbarians gradually growing into a superpower that can master right to speak in the whole world, such achievement own to the federal public's mentality of civilized and inclusive minds. However, thought liberation cannot be separated from the inheritance that the education as the carrier. Obviously, the education is very important to the country, to the society and to the individual. No matter how poor we may be, we cannot only accept the poor education. Actually, education has always been taken seriously, because it can produce immeasurable positive external effects, namely, the function of education. The ancients have done a very refined summary to the teacher: "the teacher, proselytizes, instructs, dispels doubt." In fact, the function of education also can be summed up in these three groups of words. In the academic context and phylum in our country, the function refers to the objective material's ability that can act on other objects in the environment; its objective attribute is beyond the will of human beings.
American sociologist Morton had list the terms that often mixed with function, such as purpose, utility, aim, motivation, intention, goal, consequences and so on. He also thought that the concept of function related to the view of the observers or researchers, but not necessarily involved in the view of participants. [1] Other scholar has carried on the definition of function from the angle of philosophy and science. He thinks that function is inherent to anything, is a fundamental attribute, the function is percept by outsiders through the mutual connection and interaction among things. [2]

The definition of function has not been accurate, neither the function of education is. In the face of indecisive, changeful individual thought and group phenomenon, the analysis of the function of education is much more complicated, but it is also one of the meanings of the research. As early as in primitive society, education was born with labor. In the social form of the most simple production relationship, people only depend on simple labor for a living, the duplication and transfer of labor means the continuation of life, the pass way is the simple action and imitation, it is the most primitive education in the mankind history. With the development of production tools and methods, agriculture got great development, human society entered the Neolithic age, human survival life got residence to recuperate. It is because the accumulation and transmission of people's life experience, their lives improve. And education has played a key role in it. In the late agricultural society, the social relations increasingly become complex, the concept of class began to sprout, the spiritual function of education continuously emerging, education has become means and tools for the emerging class for their special status to rebuttal. In class society, education is the social privileges form of monopoly that not everyone can accept that, its function reveals the instrumental characteristics of spiritual enslavement and class oppression, the education value of ruling class lies in its cultivating function and political function. The wave of the industrial revolution expands the scope of the function of education, today's scientific and technical revolution makes the function of education more focus on the mastery of personal value.

\section{The Positive Function of Education}

Durkheim thinks that education is that the elder instill idea and impose consciousness to the younger, because the younger generation is lack of social experience, its aim is to inspire and promote the physical and mental condition and the moral level of the next generation, enable them to adapt to the environment, 
conform to the inherent requirements that public order and good customs need, have the peculiarity that the social citizens should have. [3]

Parsons summarizes that the main functions of school and class which serve as the carrier of education is social function and selection function. The social function is reflected in the guidance of think and cultivation of personality for the juveniles, which makes them independence in the face of social affairs as soon as possible; the selection function is reflected in manpower allocation.[4]

$\mathrm{Hu}$ Guiyong focuses that the function of education on the advantageous effects that the subject and environment object generated. The advantageous effect is produced in the process of interaction between subject and environmental object, on the one hand, it accelerates the speed of the individual growth; on the other hand, it maintains the normal operation of the whole society. [5]

Humboldt sums up the functions of education of shaping the personality and cultivating the morality, especially the higher education; its ultimate goal should be the personality development, even the national spirit activation. [6] As the same, Chen Hongjie has the similar idea. In his understanding, the ultimate goal of self-cultivation is achieved through individual self-development and improvement to the realm of the moral, but the education should highlight the value of the individual, people should pursue the free and all round development.[7] Veblen thinks that the function of education is aimed at exploring and pursuing for knowledge, focuses on the study of purely academic. [8] The famous scholar Cai Yuanpei has expressed similar views, in 1918 and 1919, the opening ceremony of Beijing University, he repeatedly stressed that university is the authority for the study of the pure knowledge. [9] Vanhise tends to the definition of pragmatism function of education. He points out that the function of education is to promote the development of economy and the improvement of the social life quality.[10] Kerr is also person who is a pragmatist function of education. He concludes the different institutions of higher learning's functions as a huge function network into productive function, consumer function and citizen function. [11]

\section{The Negative Function of EduCAtion}

The views above belong to the positive function of education view; however, some scholars study of the negative functions that the education caused.

Merton proposed two groups of concept, the positive function and negative function, dominant function and recessive function. [12] The Japanese education sociologist Shibano Masaama is early to explore the negative function of education according to the views. He divides the functions of school education into four parts, the dominant positive function, recessive positive function, dominant negative function, recessive negative function, and points out in theory that the negative and positive function of education are existed in the system of educational function. [13]

The domestic scholar Chen Yilin is aware of the negative function of education as early as in 1933, he concludes the negative function to keep the inherent culture and implant impractical ideals. At the end of July in 1990, the national conference on education theory of the middle-aged and young held in Chengdu, many scholars widely realized the duality of education, they agreed that the education affects our human society, if do well, it has positive function; on the contrary, it has negative function.

Ilic strongly attracts and criticizes the contemporary higher education. In his views, the current higher education largely suppress the students' individual character and innovation. Students are cheated in the campus. University plays a role that beautify the society myth which filled with kinds of realistic contradictions and spread it, at the same time, it is a place where kinds of ceremonies implement. [14] Once the quality of education reduces or is utilized by the people with ulterior motives, the function of education is likely to be from positive to negative. The negative function of education can bring serious consequences, it is reflected to a kind of negative, hatred emotion, and it is extremely disadvantage for the construction of democratic society. Umbrella Movement in Hong Kong and the legislature occupy event in Tai Wan are typical cases, most of participates are college students. Of events in Hong Kong and Taiwan students to capture the legislature event is a very typical case, the two incidents are the main participants are college students.College students eagerly yearn for a democratic society, they are proud and self-satisfied and full of zeal, and they are easily agitated and get taken advantage of by others. But in a so-called democratic movement, they almost cannot have clear understanding of the nature of the movement, and in the process, those politicians who want to cause chaos and havoc, even the secessionists in the name of democracy through preaching to educate these young people to recognize the society, and then, the concept of idea and slogan rooted in the part of the students and spread as the virus, finally forming a serious movement. We do not want to see such a scene, therefore, the development direction and degree of goal realization of the whole country and nation, in some extent, depend on whether the negative of education can eliminate.

\section{CONCLUSION}

It takes ten years to grow trees, but a hundred to cultivate people. How important is education to the existence and development of human society is obvious, and the continuation and glorious of human civilization largely depends on education. Both basic education and higher education affect the growth of the individual, especially affect their concept. A thought, a kind of cognitive and a kind of ideology is very difficult to change once they are formed; action and words are dominated by thoughts. Now, in transition of Chinese society, there are various social problems to some extent because of not suffering from poverty but afraid of inequality such thought, success and money worship pervaded the whole society, power and money have become the only yardstick of success, people are in a extremely unsafe environment, everyone's idea are pulling between the transition period and social reality, and the basic cause of the aberrant thought can be attributed to the deviation of the educational function. In addition, the school is the main place for the individual to accept education, but the education behavior can occur at any one moment in life, the government can stipulate the syllabus and the examination 
form but cannot control everything as instruction model, however, the educational function has two sides, we still have a long way to go. For the moment, the government should reexamine the current educational situation, standing on the strategy of four comprehensive, through complete and systematic form to make the education actually work.

\section{REFERENCES}

[1] (American)Robert King Merton, translated by He Fanxing. Theoretical sociology[M]. Beijing: Hua Xia Press, 1990.

[2] Hu Dehai. On function of education. [J]. The journal of Northwest Normal University( social science), 1999,(2):41.

[3] Emile Durkheim. Education, its properties and function.[A]. Edited by Zhang Renjie. Basic writings on foreign sociology of education[J]. Shang Hai: East China Normal University Press, 1989.

[4] Cai He. Review on Modern sociology[M]. He Fei: An Hui People's Press, 1992.

[5] Hu Guiyong. Review on the fuction of education[J]. Global Education, 2004,33(7): 59-62.
[6] Humboldt, W. V. Schriften zur Anthropologie und Bildung [M]. Frankfurt : [sine loco], 1984.

[7] Chen Hongjie. The view on German classic university and its effects on China[M]. Beijing: Peking University Press,2006

[8] Veblen, T. The Higher Learning in Amercia [M]. New York : W. Huebsch, 1918.

[9] Gao Pingshu. The complete works of Cai Yuanpei: Vol.III[M].Beijing: The Chinese Publishing House, 1984.

[10] Zhang Guoqiang. The history of function view of Higher Education[J]. Modern Higher Education, 2011,4: 27-31.

[11] Kerr, C. The Great Transformation in Higher Education : 1960-1980 [M]. Albany : State University of New Nork Press, 1991.

[12] (American)Robert King Merton, translated by He Fanxing. Theoretical sociology[M]. Beijing: Hua Xia Press, 1990.

[13] Wang et al. The Review on function of education[J]. Journal of ChangZhou engineering and technology ,2004,17 (3) : 84 .

[14] Shan Zhonghui et al. The Masterpiece of western Educational[M]. Nan Chang: Jiang Xi People's Press,2000. 